Discussion Paper No. 07-007

New Insights on Unemployment Duration and Post Unemployment Earnings in Germany:

Censored Box-Cox Quantile Regression at Work

Bernd Fitzenberger and Ralf A. Wilke

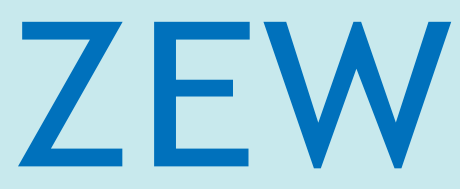

Zentrum für Europäische Wirtschaftsforschung $\mathrm{GmbH}$

Centre for European

Economic Research 
Discussion Paper No. 07-007

\section{New Insights on Unemployment Duration and Post Unemployment Earnings in Germany: \\ Censored Box-Cox Quantile Regression at Work}

Bernd Fitzenberger and Ralf A. Wilke

Download this ZEW Discussion Paper from our ftp server:

ftp://ftp.zew.de/pub/zew-docs/dp/dp07007.pdf

Die Discussion Papers dienen einer möglichst schnellen Verbreitung von neueren Forschungsarbeiten des ZEW. Die Beiträge liegen in alleiniger Verantwortung der Autoren und stellen nicht notwendigerweise die Meinung des ZEW dar.

Discussion Papers are intended to make results of ZEW research promptly available to other economists in order to encourage discussion and suggestions for revisions. The authors are solely responsible for the contents which do not necessarily represent the opinion of the ZEW. 


\section{Non-technical Summary}

This paper analyzes the determinants of unemployment duration and post unemployment wages in West Germany for inflows into unemployment during the years 1996 and 1997. We focus on the effect of the length of entitlement periods for unemployment benefits and the size of unemployment benefits. We use the German administrative individual data with information on the entitlement length for unemployment benefits and the level of unemployment benefits. In our empirical analysis of unemployment duration we apply recently developed methods which are based on quantile regression. We reason that these methods are able to capture a variety of effects which are suggested by economic theory.

Our estimation results suggest that the length of entitlement periods has only a weak effect on the conditional distribution of unemployment duration of the aged 2649. Moreover, we do not find that individuals with longer entitlement lengths for unemployment benefits have considerably higher post unemployment earnings.

There are further important effects. Unemployed with a low level of unemployment benefit transfers show much longer unemployment duration. A low level of unemployment benefits is often a proxy for supplementary public assistance resulting in a higher effective replacement ratio compared to effective replacement ratio associated with higher unemployment benefits. For this reason incentives are lower to leave unemployment. Our analysis of post unemployment earnings shows that typically the increase in wages after unemployment is higher for this group than for other groups. Other estimated effects of the unemployment insurance are mainly insignificant or small. We find evidence for a negative relationship between long term unemployment and post unemployment wages.

We observe that estimated coefficients with market policy relevance can vary over two definitions of unemployment used in the paper. This highlights the importance to address data quality issues in applied econometric research. It shows that incomplete information about individual employment trajectories due to missing spell information in administrative data - even in presence of detailed information about policy interventions - may prevent us to obtain precise estimates of the effect of policy interventions. Our analysis of unemployment duration provides empirical evidence for the inappropriateness of the proportional hazard assumption which is very popular in applied duration analysis. 


\title{
New Insights on Unemployment Duration and Post Unemployment Earnings in Germany: Censored Box-Cox Quantile Regression at Work*
}

\author{
Bernd Fitzenberger ${ }^{\dagger}$ and Ralf A. Wilke
}

March 2007

*We thank Stefan Bender, Christina Wübbecke, and the Employment Agency Mannheim for many help with the data, Xuan Zhang for sharing the program code and Eva Müller for research assistance. We thank Dragana Djurdjevic, Jenny Hunt, Bruce Meyer, Kostas Tatsiramos, and the participants of numerous workshops and seminars for helpful comments or discussions on the paper. The authors gratefully acknowledge financial support by the German Research Foundation (DFG) through the research project Microeconometric modelling of unemployment duration under consideration of the macroeconomic situation which was carried out at the ZEW Mannheim. This work uses the IAB employment subsample 1975-2001 with anonymous and original variables. The delivery and the use of the data is in compliance with $\S 75$ SGB X. The IAB does not take any responsibility for the use of its data.

${ }^{\dagger}$ Goethe University Frankfurt, ZEW, IZA, IFS. Address: Department of Economics, GoetheUniversity, PO Box 111932 (PF 247), 60054 Frankfurt am Main, Germany. E-mail: fitzenberger@wiwi.uni-frankfurt.de

${ }^{\ddagger}$ Corresponding author: University of Leicester, Department of Economics, University Road, Leicester LE17RH, UK, E-mail: raw27@le.ac.uk 


\begin{abstract}
In light of nonstationary search theory (van den Berg, 1990), this paper estimates the effects of benefit entitlement periods and the size of unemployment benefits on unemployment durations and post-unemployment earnings in West Germany. For the unemployment duration, we estimate censored Box-Cox quantile regression, which is robust with respect to the specification of the unobserved error distribution and avoids the common proportional hazard assumption. Our results suggest that the length of benefit entitlement is only of minor importance for the duration of search unemployment and for post unemployment wages. A high wage replacement rate in the low wage sector seem to considerably elongate the duration of unemployment and it is associated with higher post unemployment wages.
\end{abstract}

Keywords: Box Cox quantile regression, hazard rate, unemployment, wage JEL: C13, C14, J64 


\section{Introduction}

This paper analyzes the determinants of unemployment duration and post unemployment wages in West Germany for inflows into unemployment during the years 1996 and 1997. We focus on the effect of unemployment benefits. Income support for the unemployed in Germany comes from three sources. During the benefit entitlement period, which depends on the length of previous employment, the unemployed are entitled for benefits which are related to their previous earnings as insurance payments. After the end of the benefit entitlement period, the unemployed may receive the lower unemployment assistance, which is means tested. In addition to receiving unemployment benefits or unemployment assistance, an unemployed may receive supplementary public assistance, which is also means tested. We use unique administrative data from the unemployment insurance records involving the actual level of unemployment benefits, unemployment assistance, and the length of benefit entitlement periods. To our knowledge, this is the first study for Germany which uses administrative information on these variables. Changes in benefit levels over the course of an unemployment spell are a feature of all unemployment insurance systems around the world. ${ }^{1}$ Hence, our analysis for Germany should be of broader interest for other countries.

There exists already a large literature on the effects of unemployment benefits on the duration of search unemployment. ${ }^{2}$ Meyer (2002) and OECD (2003) provide recent surveys on the effects of unemployment benefits on the duration of unemployment. Empirical studies for the US find significantly positive elasticities of duration with respect to the potential duration of benefits. Meyer (1990) uses institutional changes as a natural experiment to identify the effect of changes in unemployment insurance on unemployment duration in a hazard rate model. The study finds that an increase in the entitlement period by 1 week results in increase of unemployment duration by 0.1 to 0.2 weeks. Narendranathan, Nickell and Stern (1985) estimate a proportionate hazard rate model with time varying benefits levels and time varying coefficients for the UK. The authors find a positive elasticity of unemployment duration for men with respect to the level of unemployment benefits. They do not find an impact for the long term unemployed. Based on a non-stationary job search model, van den Berg (1990)

\footnotetext{
${ }^{1}$ See the survey in Meyer (2002). Van den Berg (1990) estimates a structural model for data from the Netherlands in the 1980's, where the institutional setup with an interaction of unemployment benefits and public assistance was fairly similar to Germany in the 1990's.

${ }^{2}$ We mean by search unemployment that we focus on unemployed who are still likely to look for new jobs. In the German institutional setup, it is likely that a sizeable group of registered unemployed are not looking for new jobs.
} 
estimates a structural search model with time varying benefits and a time invariant wage offer distribution for the Netherlands. The study shows that the size of benefits after two years, when transfers were reduced to the level of public assistance, affects hazard rates considerably more than the benefit level during the first two years. Van Ours and Vodopivec (2006a,b) provide quasi-experimental evidence for Slovenia that a reduction in benefit entitlement periods strongly increased job finding rates, whereas the quality of the post-unemployment jobs remained unaffected. The paper finds that the change had no effect on either the type of the contract (temporary vs. permanent), the duration of the postunemployment jobs, or the wage earned in this job. In contrast, based on the European Community Household Panel for eight countries, Tatsiramos (2006) finds there is a positive indirect effect of unemployment benefits on subsequent employment duration. This effect is pronounced in countries with relatively generous benefit systems like Germany.

The literature for Germany provides conflicting evidence: Some studies find a positive relationship between the length of unemployment benefit entitlements and unemployment duration (Hunt, 1995, Plassmann, 2002; Steiner, 1997, 2001). In some studies, the results depend on the specific sample or on the definition of unemployment in the data (Fitzenberger and Wilke, 2006b, Lee and Wilke, 2005), while there are also studies which do not find any effects (Decressin, 2001; Schneider and Hujer, 1997). Hunt (1995) analyzes the effects of the extension of benefit entitlement periods for older workers during the 1980's on the hazard rates from unemployment using data from the German Socioeconomic Panel (GSOEP). She uses a difference-in-differences estimator based on interaction effects between age groups and time. The analysis finds some significant positive effects of potential duration of benefits in Germany on the actual duration of unemployment, but the standard errors of the estimated effects of benefit durations are fairly high. Decressin (2001) tries to replicate Hunt's (1995) results. She uses longer data from the GSOEP and pools data from West Germany for 1984 to 1996 with data from East Germany for 1992 to 1996. She redefines the treatment of longer benefit duration by interacting it with dummy variables of actual benefit receipt. The study concludes that the extensions of benefit duration in the 1980s did not increase the duration of unemployment. ${ }^{3}$ For older workers above an age of 49 , the extension of benefit entitlement periods was associated with a strong increase in early retirement (this issue is already discussed by Hunt, 1995). Based on administrative

\footnotetext{
${ }^{3}$ Similar to Decressin (2001), Schneider and Hujer (1997) using GSOEP data and Weber (1999) using administrative data do not find effects of the institutional changes on the duration of unemployment until a new job is found.
} 
data, Fitzenberger and Wilke (2006b) conclude that in fact the actual duration until a job is found was not strongly affected by the extensions of benefit duration for older worker. The conflicting evidence based on the GSOEP might be due to a number of data problems, such as small sample sizes (Hunt, 1995; Decressin, 2001), heaping effects (Steiner, 1997; Schneider and Hujer, 1997), and recollection error (Jürges, 2005). There exist a smaller literature on the relationship between unemployment benefits on post unemployemnt earnings in Germany. Using the GSOEP, Gangl (2002) finds positive effects of longer entitlement periods for unemployment benefits on the quality of subsequent jobs regarding the wage level and the stability of employment (see also Tatsiramos, 2006, as mentioned above). Using administrative data, Fitzenberger and Wilke (2006b) find no such effects in response to the changes of benefit durations over time.

Though not stated explicitly in some cases, a large part of the empirical literature bases the reduced form analysis of the duration of unemployment and post unemployment outcomes on a stationary search model. However, with anticipated changes in the benefit level over the course of an unemployment spell, the search behavior of the unemployed should be analyzed using nonstationary search theory, as discussed among others in van den Berg (1990) or Moffitt (1985). ${ }^{4}$ These authors state that modelling hazard rates as functions of contemporaneous covariates with constant coefficients is insufficient in such a nonstationary environment. Building on van den Berg (1990), we discuss the implications of nonstationary search theory on the empirical analysis of unemployment durations and post unemployment wages in section 2. We argue that standard proportionate hazard rate models have to be modified in complex ways (something which is typically not done in applied work) to account for nonstationary search. We suggest that estimating flexible quantile regressions of durations of unemployment is a fruitful alternative for a reduced form analysis of unemployment duration. Van den Berg (1990) estimates a structural model to account for nonstationary search, which he himself refers to as an empirical illustration. ${ }^{5}$ Our data is too limited to estimate a structural model, i.e. we would not want to make the rigid modelling assumptions typically necessary to implement a structural model with such data.

Models for duration data are typically estimated using accelerated failure time model or proportional hazard models, see van den Berg (2001) as a recent survey. Quantile regression has been emerging as an attractive alternative (Koenker and Bil-

\footnotetext{
${ }^{4}$ See also the earlier literature cited in van den Berg (1990).

${ }^{5}$ The structural model estimated in van den Berg (1990) is build on the assumption of a timeinvariant wage offer distribution and on information in the data involving subjective expectations about the offer wages by the unemployed.
} 
ias, 2001; Koenker and Geling, 2001; Portnoy, 2003). Fitzenberger and Wilke (2006a) provide a recent survey on the use of quantile regression for duration analysis. Quantile regression model the changes of quantiles of the conditional distribution of the duration in response to changes of the covariates. This paper applies Box-Cox quantile regression (Powell, 1991; Buchinsky, 1995; Machado and Mata, 2001) as a flexible approach to model the impact of time invariant covariates on durations. This approach allows for impacts of covariates to change with the elapsed duration, thus allowing for flexible duration dependence specific to the individual observed covariates, a feature which is quite appealing in light of nonstationary search theory. A quantile regression models the distribution of the duration in a more flexible way than accelerated failure time models or the Cox proportional hazard model because they do not restrict the variation of estimated coefficients over the quantiles.

In search theory and in applied duration analysis, there is a strong focus on hazard rates. Quantile regression estimates can be used to infer the implied hazard rate by the elapsed duration of unemployment depending on an individuals characteristics. Machado and Portugal (2002) and Machado, Portugal, and Guimarães (2006) have introduced a simple simulation method to obtain the conditional hazard rates implied by the quantile regression estimates. This paper uses a slightly modified version of their estimator introduced in Fitzenberger and Wilke (2006a). The modifications are necessary to account for censored data and to fix a general smoothing related finite sample problem. Using this method, it is straightforward to analyze duration dependence without having to assume that the pattern estimated for the so-called baseline hazard in proportional hazard rate models applies uniformly to all observations with different covariates.

In our application, we use the IAB employment subsample (IABS). ${ }^{6}$ We use additional variables with exact information about the entitlement length for unemployment benefits and the level of unemployment compensation. These data allow us to investigate effects of the unemployment insurance system on the distribution of unemployment duration and on post unemployment wages in Germany. Important limitations persist such as that the data do not identify the true length of unemployment duration (Fitzenberger and Wilke, 2006b; Lee and Wilke, 2005). We take account of this problem and check the robustness of our empirical results with respect to the definition of unemployment in the data.

This paper extends previous studies in three aspects: First, we apply censored Box-

\footnotetext{
${ }^{6}$ The IAB-Beschäftigtenstichprobe (IABS) of the data research center (FDZ) of the BA at the Institut für Arbeitsmarkt- und Berufsforschung (IAB).
} 
Cox quantile regression (Powell, 1991) for unemployment duration, which contains the linear and the log linear model as special cases. This method allows for new insights into the conditional distribution of unemployment duration compared to former studies for Germany (Hunt, 1995; Hujer and Schneider, 1997; Decressin, 2001; Plassmann, 2002 and others) who apply conventional proportional hazard models or Lüdemann et al. (2006) who apply log linear quantile regression to data without precise information about unemployment benefits. We argue that quantile regression are a fruitful approach in light of nonstationary search theory. Beyond our substantive analysis, we are the first to apply censored Box-Cox quantile regression for duration analysis. We use the algorithm developed in Fitzenberger et al. (2004), which addresses an important numerical problem arising when implementing Box-Cox quantile regression. Second, we use more recent and more comprehensive administrative data than the previous literature, since we have exact information about the size of transfer payments from the federal employment agency (Bundesagentur für Arbeit, BA) and the length of entitlement periods. Third, we present a more comprehensive analysis of post unemployment earnings by applying a variety of parametric and nonparametric methods.

Our estimation results suggest that the length of entitlement periods has only a weak effect on the conditional distribution of unemployment duration. While it is generally small for short unemployment duration, it increases for the higher quantiles of the unemployment duration distribution, in particular for the older unemployed with extended entitlement periods for unemployment benefits. In contrast, one would have expected that an increase benefit duration affects in particular the lower quantiles below two years of unemployment. The estimated effects for lower quantiles are ambiguous: they are either small or results are sensitive to the definition of unemployment. Our results therefore suggest that the true effect is rather small for early quitters of unemployment, for whom chances are very small, that they do not find a job early in their unemployment spell. There are further important effects. Unemployed with a low level of unemployment benefit transfers show much longer unemployment duration. $^{7}$ A low level of unemployment benefits is often a proxy for supplementary public assistance resulting in a higher effective replacement ratio compared to effective replacement ratio associated with higher unemployment benefits. We also analyze the effect on post unemployment wages. We observe that high replacement ratios of low wage unemployed coincide with upward movements in the earnings distribution. Other estimated effects of the unemployment insurance are mainly insignificant or small. We

\footnotetext{
${ }^{7}$ See also Lüdemann et al. (2006) or Wichert and Wilke (2005) who use the pre-unemployment wage as a proxy.
} 
find evidence for a negative relationship between long term unemployment and post unemployment wages which we take as evidence for a deterioration of the offer wage distribution over the course of an unemployment spell.

The remainder of the paper is structured as follows: Section 2 discusses nonstationary search theory and its implications on the empirical analysis of unemployment duration. Information about the data and the institutional setup is given in section 3 . The econometric framework is presented in section 4. The empirical results are given in section 5 , followed by a short summary.

\section{Nonstationary Search and Duration of Unemploy- ment}

Under the institutional setting in Germany at the end of the 1990's, benefit entitlement, as anticipated by the unemployed at the beginning of the unemployment spell, changes at a finite number of points of time and is piecewise constant otherwise. ${ }^{8}$ Apart from a possible delay in benefit entitlement at the beginning of the unemployment spell (see section 3 for further details), unemployed individuals expect benefits to be nonincreasing over time, with the exhaustion of unemployment benefits resulting in a decline of income depending on the economic situation of the unemployed's household. In this situation, the search behavior of the unemployed should be analyzed using nonstationary search theory, as discussed among others in van den Berg (1990) or Moffitt (1985). Van den Berg (1990) characterizes the reservation wage of the unemployed under perfect foresight allowing for a finite number of discrete changes in the benefit level. Under further plausible assumptions on the dynamics of the offer wage distribution and the job arrival rates, the reservation wage changes continuously over time (Theorem 1 in van den Berg, 1990). In fact, the reservation wage will decline with elapsed duration of unemployment because the benefit level is declining eventually and the offer wage distribution is likely to deteriorate over time.

Based on the theoretical considerations in van den Berg (1990), we draw the following conclusions: First, the hazard rates from unemployment to employment are likely to change continuously with elapsed duration of unemployment. Second, it remains an empirical question whether the hazard rates increase or decrease over time because the deterioration of the offer wage distribution may counteract the decline in the reservation wage (this point is implicit in van den Berg, 1990, but not discussed in detail).

\footnotetext{
${ }^{8}$ Benefits can also be interrupted by sanctions, which, however, are likely to be of minor importance for our application because in many cases they are withdrawn after a few days. See Wilke (2004).
} 
Third, post unemployment wages should ceteris paribus be negatively associated with the actual duration of unemployment. Fourth, they should be positively associated with the length of benefit entitlement periods as anticipated by the unemployed at the beginning of the unemployment spell and with the size of benefits. This is the quality argument suggesting that more generous unemployment benefits result on average in a better job match (job quality) observed ex post (see Gangl, 2002). Fifth, theory does not predict an unambiguous empirical relationship between the benefit level and the duration of unemployment for the following two reasons. Unemployment benefits are positively correlated with offer wages, whereas the levels of unemployment assistance and supplementary public assistance are likely to be negatively correlated with the offer wage, because the latter are means tested.

An important conceptual insight from nonstationary job search theory is that entitlement effects, which reflect anticipated changes in the benefit level, may affect the entire distribution of the unemployment duration in a nonuniform way. Hazard rates are affected in a complex way by benefit changes depending on the elapsed duration of unemployment relative to the entitlement period and the size of transfers after a benefit change. Modeling hazard rates as functions of contemporaneous covariates with constant coefficients is insufficient in such a nonstationary environment, see van den Berg (1990, section 5.1) and Moffitt (1985). In addition, a proportional hazard assumption involving a common baseline hazard is unlikely to be plausible for a parsimonious econometric specification, since theory suggests individual starting points and individual dynamics for the reservation wage as a function of elapsed duration. ${ }^{9}$ Theory predicts further that the length of the entitlement period of a specific benefit does not affect hazard rates after the exhaustion of this benefit (van den Berg, 1990, section 3). Nevertheless, the quantiles of the duration distribution, which lie above the exhaustion period, are affected through the effect on the hazard rates before the exhaustion of benefit entitlement. ${ }^{10}$

\footnotetext{
${ }^{9}$ There have been various suggestions in the literature to address these issues within a proportionate hazard model. Narendranathan et al. (1985) use the period specific benefit level as covariates and let the coefficient change over time. This approach does not take account of the anticipation effects, resulting in a declining impact of current period benefits as the end of entitlement approaches. Hujer and Schneider (1995) use time until exhaustion of benefits to account for the changing influence on exit rates to employment over time, which allows to capture the anticipated effect of the changing benefit level. This approach restricts the influence of time until exhaustion to be the same irrespective of the total length of benefit entitlements and the size of the transfer (unemployment assitance, public assistance) after exhaustion of unemployment benefits.

${ }^{10}$ This is due to the well known relationship between the distribution function and the integrated
} 


\section{$3 \quad$ Data and Institutions}

The analysis is based on comprehensive merged administrative data with exact information about the length of entitlement periods and the level of unemployment compensation drawn by the unemployed. We use the IAB employment subsample 1975-2001 augmented by supplementary detailed information on income transfers from the federal

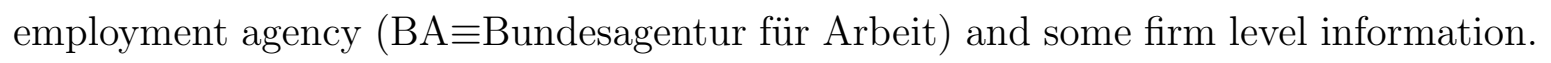
The data are a $2 \%$ random sample of employees subject to social security taxation in Germany. These spell data involve individual employment trajectories on a daily basis, combining employment periods and periods of transfer payments from the BA during the period 1975-2001 for about 1.1 Mio. individuals in West Germany (see Hamann et al., 2004 or Bender et al., 2000). ${ }^{11}$ Income transfers from the BA are unemployment benefits (UB), unemployment assistance (UA), or income maintenance during further training (IMT). Periods of self-employment and life time civil servants are not identifiable in the data. ${ }^{12}$ The data are not merged with information about employment subsidies paid by the employment agency. Hence, it is impossible to distinguish between regular and subsidized employment. Periods of unemployment without receipt of income transfers from the BA are also not identifiable.

For the reasons stated above, we cannot identify the true length of (search) unemployment spells in an economic sense, see also Fitzenberger and Wilke (2006b) and Lee and Wilke (2005). Also, since the reason for the termination of employment is not recorded, it is not possible to infer the reason for unemployment such as displacement. Missing periods in the employment trajectories, i.e. periods without employment or transfers, cause only partial identification of the unemployment period. As a natural approach, we work with different proxies for the true unemployment period: the Nonemployment (NE) proxy of Fitzenberger and Wilke (2006b) is used as an upper bound for the true unemployment duration (in the sense of first order stochastic dominance).

hazard rate, i.e. for duration $T$

$$
\operatorname{Pr}(T \leq t)=1-\exp \left(-\int_{0}^{t} \lambda(s) d s\right)
$$

where $\lambda(s)$ is the hazard rate at elapsed duration $s$.

${ }^{11}$ We exclude the data for East Germany for our analysis.

${ }^{12}$ In fact, if there is an unobserved period in the individual employment trajectory this may correspond to several labor market states: self employment, civil servant, unemployment, out of the labor force or retirement. 
Nonemployment (NE): all periods of nonemployment after an employment period which contain at least one period with income transfers by the German federal labor office. The nonemployment period is considered as censored if the last record involves a UB, UA, or IMT payment that is not followed by an employment spell. ${ }^{13}$ In such a case, we do not know whether the individual is still unemployed, out of labor force, or even self-employed. The spell is not censored if we observe later a successful exit to employment. This definition of unemployment includes the periods of nonemployment (out of the labor force, public assistance) which are not explicitly recorded in the data.

As a second proxy for unemployment in the data, we use the UPIT (Unemployment with Permanent Income Transfers) proxy of Lee and Wilke (2005) which serves as a lower bound for the true unemployment duration. This definition excludes cases where some part of the unemployment spell is not associated with income transfers from the BA. $^{14}$

Unemployment with Permanent Income Transfers (UPIT): all periods of nonemployment after an employment period with a continuous flow of unemployment compensation from the BA. The maximum interruption in compensation transfers is one month in the case of cutoff times: six weeks. An observation is marked as right censored at the last day of the duration before the transfers are interrupted for more than one month or in the event of there being no observation after the last compensation transfer.

We exclude periods of unemployment which are not directly identifiable from the data. Note that an NE spell may not fulfill the conditions of UPIT, if there is no income transfer within six weeks after the end of the employment period. For this reason unemployment spells after a voluntary job quit are excluded by the definition of UPIT (if such a voluntary nature of a quit is known to the case worker in the employment agency). This is the main reason why there are more NE spells than UPIT spells. Note also that if a spell is both UPIT and NE then its NE duration is greater than or equal to UPIT. In our econometric analysis, we argue that a result is robust with respect to the definition of unemployment, if we obtain the same estimation result for the two proxies. Such a robust result may, however, still not hold for the true unemployment duration.

\footnotetext{
${ }^{14}$ About two third in the stock of registered unemployed in Germany draw income transfers from the BA. There is no corresponding spell level information available.
} 
We impose further restrictions on the samples analyzed in order to make them more homogeneous. We only consider unemployment spells which begin with unemployment benefits as income transfer and who do not have a foregoing unemployment spell within the year before the start of the current spell. We only include spells if the last employer was located in West Germany and if the spell began in 1996 or in 1997. Furthermore, we restrict the sample to males in the age group 26 to 49 years. ${ }^{15}$ We exclude spells with recent unemployment periods from the sample in order to construct a "stable employment before unemployment design". Remaining spells have therefore longer entitlement periods than the average unemployed below 50 years. For reasons of generality, we remark that our heuristic but rather simple rule may of course exclude displaced workers and it still includes seasonal unemployment to some extent. The descriptive summary statistics of the samples is available in table 2. It is apparent that the composition of the samples for the two unemployment proxies are similar. Furthermore, there are less UPIT spell and UPIT spells are shorter.

\section{The unemployment compensation system during the 1990s}

Unemployment benefit transfers are insurance payments and socially insured employed qualify for UB entitlements if they have worked at least 12 months during the past three to seven years. Since 1994, the wage replacement ratio for unemployment benefits is $63 \%$ or $67 \%$ and the higher rate only applies in the presence of children in the household. Depending on the work history and on the age of the unemployed, the entitlement length is up to 12 months for young and mid aged (less than 42 years old) unemployed and up to 32 months for older unemployed. ${ }^{16}$ The entitlement length for unemployment benefits in Germany depends on the duration of socially insured employment during a certain base period (past seven years). Therefore only older individuals with long employment periods have extended entitlement periods ( $>12$ months). In our specific sample the maximum possible entitlement length is 26 months but there are just few observations with more than 24 months. Starting in 1997, the maximum entitlement

\footnotetext{
${ }^{15}$ We also did estimations for females. Results have often the same sign but the magnitude of estimated coefficients differ. In particular, results for females are less sharp and less clear, i.e. the estimated standard errors are greater. This is in accordance with the results of Biewen and Wilke (2005) and may be explained by family background related labor force withdrawals (see Wichert and Wilke, 2005).

${ }^{16}$ These institutional rules are valid from 1987 to 1997. General details about the German unemployment compensation system during the 1990s can be found in Decressin (2001) or in Plassmann (2002).
} 
length for unemployment benefits were reduced. ${ }^{17}$ Since this reform only applied to newly generated entitlements, effects on actual entitlement periods lag by several years. In fact, actual entitlement periods started to decrease in 1998 or even later. ${ }^{18}$ Due to its legal design, there is no incentive for anticipation effects before the reform for employees below age 50. ${ }^{19}$ Therefore, it is unlikely that the results of our analysis are affected by the reform in 1997. We also exclude the less than 26 years old from our analysis, since there is evidence that a large share of young unemployed enter subsidized employment (see Fitzenberger and Wilke, 2006a). An exit to subsidized employment is not identifiable in our data and systematic labor market policies for specific traget groups such as the young individuals would possibly causes a bias.

Comparing our sample to all unemployment spells in West Germany starting in 1996 or 1997, we observe that our sample only comprises about $12 \%$ of all IABS unemployment spells. Our sample has longer entitlement periods than the full sample (compare tables 1 and 2, appendix). Apart from the age restriction, this is mainly due to the fact that we consider unemployed with quite a stable employment history before unemployment. While preparing the data for the estimations we encountered further data quality issues. The original variable "entitlement length for unemployment benefits" contains about 50\% missing values. Since the entitlement length is not a random variable we impute the missing values by the median of the observed entitlement length conditional to age, calender year and relevant length of foregoing employment spells within the qualification period for UB. We then classified the entitlement length to four intervals. We constructed three categories for the level of unemployment compensation: low earners who are likely to receive supplementary public assistance. ${ }^{20}$ The main segment of the sample population falls into the middle interval between 25 and 40 EUR daily income transfers. The third category represents the upper tail of the distribution, i.e. the recipients of very high income transfers.

Building on the results of Lüdemann et al. (2006), we construct pooled education and business sector categories, since finer classifications suggest only minor differences in results. We also tried a number of other variables which did not yield sizeable effects. $^{21}$ Several interactions between the amount of unemployment compensation

\footnotetext{
${ }^{17}$ See Wolff (2003) for further institutional details on this issue.

${ }^{18}$ See also Wolff (2003) or Müller et al. (2007) for a microeconometric evaluation of this reform.

${ }^{19}$ See also Müller et al. (2007) who do not even find anticipation effects for those aged >50.

${ }^{20}$ The level of public assistance is such that it depends upon the household composition, other household income and on the community (see Wilke, 2006). Since it is impossible to determine recipience of public assistance from our data, we take a low level of unemployment compensation transfers as a rough proxy for supplementary public assistance.

${ }^{21}$ These variables are: unemployed in the past, location within West- or East Germany of the first
} 
received, the entitlement length, and the company size yield point estimates of high magnitude. Since there are just a few observations falling into these categories, it was not possible to achieve numerically stable results. ${ }^{22}$ For this reason, we excluded them from the analysis in this paper. A larger data set would allow one to trace out these effects more precisely.

\section{Econometric Analysis}

The empirical analysis of unemployment duration is a widely investigated field in labor market research. Nonparametric estimators are often applied for data exploration, e.g. the Kaplan-Meier estimator. They do not impose strong assumptions at the expense that they only work in very low dimensions. This implies that results have a rather descriptive nature. Comprehensive semi-parametric duration models are applied in order to control for the composition of individuals. These models often belong to the class of accelerated failure time or proportional hazard models. While it is possible to control for the composition of individuals these models clearly impose stronger assumption than nonparametric approaches. In the framework of hazard rate estimation there are two important model implications which are often subject to criticism: first, the proportionality of conditional hazard rates, the key model assumption, may not be fulfilled and second, the presence of unobserved variables even if they are independent of the observed covariates, can cause estimation bias, if one does not appropriately control for it.

In this paper, we apply censored Box-Cox quantile regression as an alternative estimator which requires less assumptions on the shape of the conditional hazard rates and which is fairly robust with respect to a random effects assumption, where the random effect is independent of the covariates (Fitzenberger and Wilke, 2006a). Based on the estimated coefficients of censored Box-Cox quantile regression, we use a modified version of the simulation approach suggested by Machado et al. (2006) to estimate conditional hazard rates. A main disadvantage of any quantile regression approach for duration analysis is that it is restricted to the case of time-invariant covariates.

employment spell of the unemployed, length of foregoing tenure (which is correlated with the entitlement length for unemployment benefits), simultaneous employment and receipt of unemployment compensation at the beginning of the unemployment and minor employment relation (Mini-Job) at the beginning of the unemployment spell.

${ }^{22}$ We first estimated a slightly simplified version of the specification described in the next section. This was done in order to keep the problem manageable in light of the huge computation time needed, see below. 


\section{Censored Box-Cox quantile regression}

We estimate nonlinear quantile regression for duration data involving the estimation of an accelerated failure time model at different quantiles $\theta \in(0,1)$ for the completed duration $T_{i}$ of spell $i$

$$
q_{\theta}\left(h_{\theta}\left(T_{i}\right) \mid x_{i}\right)=x_{i}^{\prime} \beta^{\theta}
$$

where $q_{\theta}\left(h_{\theta}\left(T_{i}\right) \mid x_{i}\right)$ is the $\theta$-quantile conditional on $x_{i}$. For a flexible transformation function $h_{\theta}($.$) , equation (1) nests the standard proportionate hazard model with time-$ invariant covariates (Koenker and Geling, 2001; Portnoy, 2003). ${ }^{23}$

We choose to specify the transformation $h_{\theta}($.$) as the Box-Cox transformation in-$ troduced by Box and Cox (1964):

$$
h(T)=T_{\lambda, i}= \begin{cases}\left(T_{i}^{\lambda}-1\right) / \lambda & \text { if } \lambda \neq 0 \\ \log \left(T_{i}\right) & \text { if } \lambda=0,\end{cases}
$$

where $\lambda \in \mathbb{R}$. Due to the equivariance property of the Box-Cox transformation, equation 1 effectively models the conditional quantiles of durations $T_{i}$ as

$$
q_{\theta}\left(T_{i} \mid x\right)=\left\{\begin{array}{ll}
\left(\lambda x_{i}^{\prime} \beta^{\theta}+1\right)^{1 / \lambda} & \text { if } \lambda \neq 0, \\
\exp \left(x_{i}^{\prime} \beta^{\theta}\right) & \text { if } \lambda=0,
\end{array},\right.
$$

provided $\lambda x_{i}^{\prime} \beta^{\theta}+1 \geq 0$ for $\lambda \neq 0$. Let the observed duration be possibly right censored in the flow sample, i.e. the observed completed duration $T_{i}$ is given by

$$
T_{i}=\min \left\{T_{i}^{*}, y c_{i}\right\}
$$

where $T_{i}^{*}$ is the true duration of the spell and $y c_{i}$ is the spell specific threshold value (censoring point) beyond which the spell can not be observed.

\footnotetext{
${ }^{23}$ For a proportionate hazard model with time-invariant covariates, define the integrated baseline hazard $\Lambda_{0}(t)=\int_{0}^{t} \lambda_{0}(\tilde{t}) d \tilde{t}$, then the following well known generalization of the accelerated failure time model holds

$$
\log \left(\Lambda_{0}\left(T_{i}\right)\right)=x_{i}^{\prime} \beta+\epsilon_{i}
$$

with $\epsilon_{i}$ again following an extreme value distribution and $\beta=-\tilde{\beta}$ with $\tilde{\beta}$ being the coefficients of the proportionate hazard model. Thus, the proportional hazard rate model implies a linear regression model for the a priori unknown transformation $h\left(T_{i}\right)=\log \left(\Lambda_{0}\left(T_{i}\right)\right)$. This regression model involves an error term with an a priori known distribution of the error term and a constant coefficient vector across quantiles, see Fitzenberger and Wilke (2006a).
} 
A censored Box-Cox quantile regression amounts to minimize the following objective

$$
\min _{\beta, \lambda} \sum_{i} \rho_{\theta}\left(T_{i}-\min \left[\left(\lambda x_{i}^{\prime} \beta+1\right)^{1 / \lambda}, y c_{i}\right]\right)
$$

where the check function is given by $\rho_{\theta}(t)=[\theta I(t \geq 0)+(1-\theta) I(t<0)]|t|$ and $I($. denotes the indicator function.

Chamberlain (1994) and Buchinsky (1995) suggest a numerically attractive two step procedure to implement a Box-Cox quantile regression, which exploits the equivariance property of quantiles. In a practical implementation, it is not guaranteed that $\lambda x_{i}^{\prime} \beta+$ $1 \geq 0$ holds for all observations during the iteration of the optimization problem to the solution or even for the final estimator. Fitzenberger et al. (2004) analyze in detail this numerical problem, which had been ignored in the literature before. The study suggests a simple modification of the two step procedure by Chamberlain and Buchinsky and shows its good numerical properties by means of a simulation study. For the empirical results presented in this paper, we use the straightforward adaptation of the procedure suggested in Fitzenberger et al. (2004) to the case of censored Box-Cox quantile regression, see appendix I. Based on Machado and Mata (2000) and recently Fitzenberger et al. (2004), our implemention of censored Box-Cox quantile regression yields a $\sqrt{N}$-consistent estimator and the asymptotic covariance matrix follows from standard considerations for nonlinear estimation. In our application, the censored Box-Cox quantile regressions requires a huge computational effort. For this reason we estimate censored Box-Cox quantile regression on a quantile grid on $[0.06,0.9]$ with step size 0.01 .

\section{Conditional nonparametric hazard rates}

Duration analysis often focuses on conditional hazard rates which can be derived from the distribution of unemployment duration conditional upon covariates. Machado and Portugal (2002) and Machado et al. (2006) suggest a resampling procedure (henceforth denoted as MPG) to obtain the hazard rates implied by the estimated quantile regression. Zhang (2004) and Fitzenberger and Wilke (2006a) suggest a modified version for right censored data. The main idea of the MPG is to simulate data based on the estimated quantile regressions for the conditional distribution of $T_{i}$ given the covariate and to estimate the density and the distribution function directly from the simulated data.

In detail, MPG is adapted to censored Box-Cox quantile regressions as follows (see Machado and Portugal, 2002; Machado et al., 2006; Fitzenberger and Wilke, 2006a): 
1. Generate $M$ independent random draws $\theta_{m}, m=1, \ldots, M$ from a uniform distribution on $\left(\theta_{l}, \theta_{u}\right)$, i.e. extreme quantiles with $\theta<\theta_{l}$ or $\theta>\theta_{u}$ are not considered here. $\theta_{l}$ and $\theta_{u}$ are chosen in light of the type and the degree of censoring in the data. Additional concerns relate to the fact that quantile regression estimates at extreme quantiles are typically statistically less reliable, and that duration data might exhibit a mass point at zero or other extreme values. The benchmark case with the entire distribution is given by $\theta_{l}=0$ and $\theta_{u}=1 .^{24}$

2. For each $\theta_{m}$, estimate the censored Box-Cox quantile regression model obtaining $M$ vectors $\beta^{\theta_{m}}, \lambda_{\theta}$.

3. For a given value of the covariates $x_{0}$, the sample of size $M$ with the simulated durations is obtained as,

$$
T_{m}^{*} \equiv \hat{q}_{\theta_{m}}\left(T \mid x_{0}\right)=\left(\lambda_{\theta} x_{i}^{\prime} \beta^{\theta}+1\right)^{1 / \lambda_{\theta}} \quad \text { with } \quad m=1, \ldots, M
$$

We use the same adjustment as described in appendix I when $\lambda_{\theta} x_{i}^{\prime} \beta^{\theta}+1<0$.

4. Based on the sample $\left\{T_{m}^{*}, m=1, \ldots, M\right\}$, estimate the conditional density $f^{*}\left(t \mid x_{0}\right)$ and the conditional distribution function $F^{*}\left(t \mid x_{0}\right)$.

5. The hazard rate conditional on $x_{0}$ and conditional on the durations drawn in the interval $\left(\theta_{l}, \theta_{u}\right)^{25}$ is estimated by

$$
\hat{\lambda}_{0}(t)=\frac{\left(\theta_{u}-\theta_{l}\right) f^{*}\left(t \mid x_{0}\right)}{1-\theta_{l}-\left(\theta_{u}-\theta_{l}\right) F^{*}\left(t \mid x_{0}\right)}
$$

MPG uses a kernel estimator for the conditional density

$$
f^{*}\left(t \mid x_{0}\right)=\frac{1}{M b} \sum_{m=1}^{M} K\left(\frac{t-T_{i}^{*}}{b}\right)
$$

where $b$ is the bandwidth and $K($.$) the kernel function. Based on this density estimate,$ the distribution function estimator is

$$
F^{*}\left(t \mid x_{0}\right)=\frac{1}{M} \sum_{m=1}^{M} \mathcal{K}\left(\frac{t-T_{i}^{*}}{b}\right) \quad \text { with } \quad \mathcal{K}(u)=\int_{a}^{t} K(v) d v
$$

\footnotetext{
${ }^{24}$ In our application, $\theta_{l}=0.06$ and $\theta_{u}=0.9$, see above. Random numbers are then drawn from a discrete uniform distribution which has the quantile grid points as support points. This increases computation time significantly at the cost of small approximation errors.

${ }^{25}$ Simulating the full distribution $\left(\theta_{l}=0\right.$ and $\left.\theta_{u}=1\right)$, it follows by definition: $\hat{\lambda}_{0}(t)=f^{*}\left(t \mid x_{0}\right) /[1-$ $\left.F^{*}\left(t \mid x_{0}\right)\right]$.
} 
Machado and Portugal (2002) and Machado et al. (2006) suggest to start the integration at zero $(a=0)$, which is probably motivated by durations being strictly positive. However, the kernel density estimator also puts probability mass into the region of negative durations, which can be sizeable with a large bandwidth, see Silverman (1986, section 2.10). For this reason, we use a kernel density estimator based on log durations. This is possible when observed durations are always strictly positive, i.e. there is no mass point at zero. The estimates for density and distribution function for the duration itself are easily derived from the density estimates for log duration by applying an appropriate transformation. ${ }^{26}$

\section{$5 \quad$ Empirical Results}

We first investigate the duration of unemployment and then post-unemployment earnings.

\subsection{Unemployment Duration}

The estimation of the censored Box-Cox qunatile regression for both definitions of unemployment Nonemployment (NE) and Unemployment with Permanent Income Transfers (UPIT) took us about three months on a Xeon $2.4 \mathrm{GHz}$ with TSP 4.5 for Linux. ${ }^{27}$ Figure 1 presents the estimated coefficient of the Box-Cox transformation. The estimated $\lambda$ increases from quantile 0.2 to 0.9 , while there is no clear pattern for the lowest quantiles. The results suggest a linear relationship $(\lambda=1)$ for the highest quantiles and a $\log$-linear relationship $\lambda=0$ ) for quantiles in the range 0.3 to 0.6 . Results for the lowest quantiles do not show a clear-cut pattern. There were some numerical problems at low quantiles for UPIT which we believe to have addressed in a satisfactory way. ${ }^{28}$ For the lowest quantiles the estimation results for the lambda coefficients (and simultaneously for the $\beta$-coefficients) appear to be quite volatile over the quantiles. At the same time, however, the predicted duration still varies smoothly over the quantiles

\footnotetext{
${ }^{26}$ Silverman (1986, section 2.10) discusses further alternatives for this problem.

${ }^{27}$ For this reason, we are only able to present bootstrap standard errors for a small number of cases.

${ }^{28}$ In the case of UPIT, the censored quantile regression estimator did not converge for low quantiles in some cases. This is surprising since the problem of right censoring should be negligible for low quantiles. To overcome these, we estimated standard (non-censored) quantile regressions in these problematic cases. This approach is justified because only 2 to $4 \%$ of the fitted values lie above the censoring point of the corresponding observation. Note that censored quantile regression corresponds to a standard quantile regression when all fitted values of the censored quantile regression lie below the respective censoring point.
} 
because the variation in $\lambda$ and $\beta$ balances out.

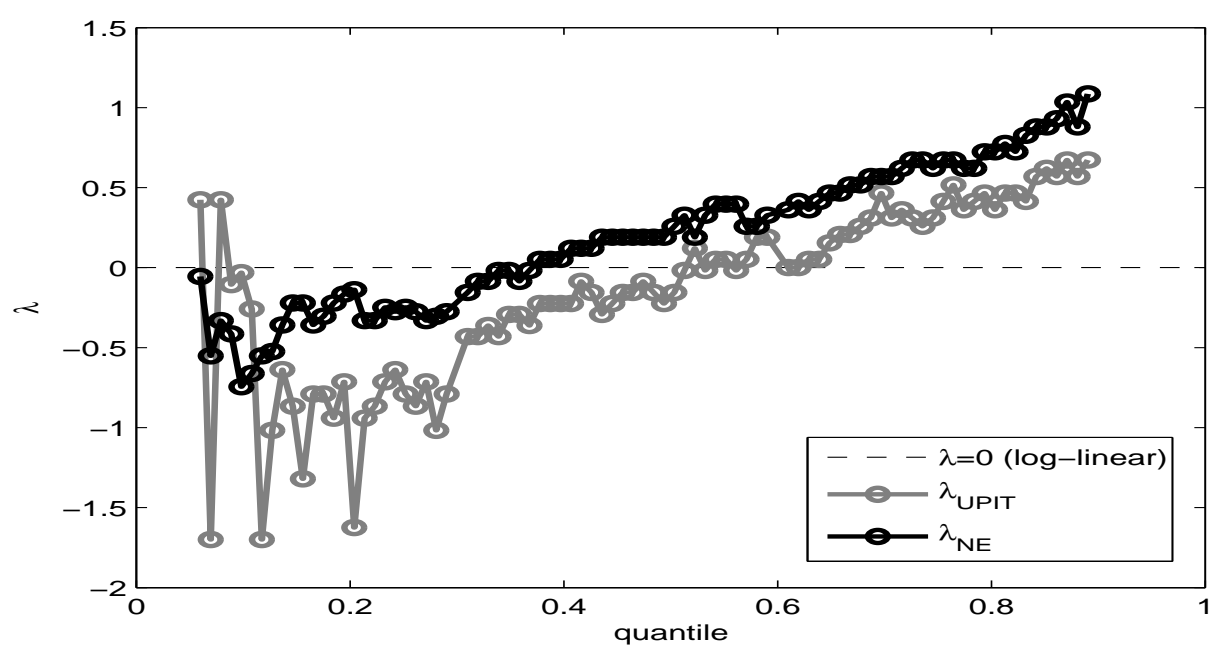

Figure 1: Estimated Box Cox transformation coefficient $\lambda$.

To assess the impact of the covariates on unemployment duration it does not suffice to consider the $\beta_{\lambda, \theta^{-}}$coefficients alone. Therefore, we compute local partial effects by the estimated percentage change of the conditional quantile function when the $k^{\prime}$ th regressor switches from 0 to 1 (note that all covariates are dummy variables). This may be written as $\left(\hat{q}_{\theta}\left(T \mid x_{1}\right)-\hat{q}_{\theta}\left(T \mid x_{0}\right)\right) / \hat{q}_{\theta}\left(T \mid x_{0}\right)$, where $x_{0}$ and $x_{1}$ are vectors of regressors which only differ in the $k^{\prime}$ th element. We compute the change at the sample mean of the other regressors. Due to the huge computational effort, it is not possible to report comprehensive standard errors. Table 3, however, presents estimated standard errors for selected quantiles using 50 bootstrap resamples of the NE data. It is evident that many estimated effects are likely to be significant and that standard errors increase at the upper quantiles.

The estimated partial effects for all covariates are displayed in figures 3 and 4 in the appendix. It is apparent that older unemployed, unemployed with very long entitlement periods for unemployment periods, who worked in a large company or who receive a low level of unemployment benefit transfers have considerable longer unemployment periods. Some of these estimates may be affected by early retirement or by individuals who actually withdraw from the labor force. Low earning individuals before unemployment are likely to be entitled to supplementary public assistance. Thus, this group of unemployed has typically a considerably higher wage replacement ratio (even larger than one is possible) than the other unemployed. This generates disincentives for accepting new jobs because of high reservation wages (Christensen, 2005). Our results 
therefore confirm rather descriptive evidence of Wichert and Wilke (2005), who apply a bivariate nonparametric model. Unemployment related to seasonal unemployment or to temporary lay-offs is shorter (winter, recall, agriculture, construction). Surprisingly this is still present to some extent in our sample even after conditioning on not receiving unemployment benefits in the year prior to current unemployment. ${ }^{29}$

The estimated hazard rates (see figure 2) based on the MPG procedure further illustrate these findings using a different representation. Interestingly, several profiles for hazard rates are not proportional to other estimated profiles. In some cases, we even find crossings. This suggests that a proportional hazard model is not empirically supported by our results. Moreover, we do not observe peaks in the nonparametric hazard rates at the points when the unemployment benefits entitlement period exhausts, e.g. after 12 months of unemployment.

Let us interpret further the results for unemployment benefits and entitlement periods in light of the theoretical discussion in section 2 on nonstationary search theory. Based on the partial effects displayed in figures 3 and 4 and the associated standard errors reported in table 3 for some cases there are noticeable differences across quantiles. Entitlement periods between 6 and 12 months do not increase unemployment duration relative to the reference case 1 to 6 months. ${ }^{30}$ This is confirmed by the estimated hazard rates. An extended benefit entitlement period between 12 and 18 months, however, results in a significantly longer unemployment duration and lower hazard rates. However, the absolute size of the effect of benefit entitlement periods is fairly small (at most 20 days for the group with 12 and 18 months).

Despite the volatility of the estimated partial effects, the estimated hazard rates are very smooth (of course this is partly the result of kernel smoothing involved in the MPG procedure) and show that hazard rates are lower with longer benefit entitlement periods. The effect is even stronger for a benefit entitlement period above 18 months. All estimated hazard rates are falling over time and the decline is steeper at early durations. In accordance to nonstationary search theory, our results suggest that unemployed do not wait systematically until the end of the benefit entitlement period before they accept a new job. However, nonstationary search theory would also

\footnotetext{
${ }^{29}$ Lüdemann et al. (2006) obtain similar results using all unemployment spells starting in the period 1981-1995 of the 26-41 years old using a log-linear censored quantile regression model. However, the magnitude of their estimated effects differ in several case. This may be explained by different samples or by their less flexible econometric specification.

${ }^{30}$ If anything, the longer benefit entitlement (especially for UPIT) seems to be associated with shorter unemployment duration, a result with can only be rationalized as a remaining sorting effect despite conditioning on a stable employment history before the beginning of unemployment.
} 
predict that hazard rates of unemployed with different entitlement periods should converge ceteris paribus with elapsed unemployment duration because the search behavior of those with longer entitlement periods converges to the search behavior of unemployed without unemployment benefits (possibly receiving unemployment assistance or public assistance) with elapsed duration. However, the estimated hazard rates evolve almost in parallel fashion for the unemployed with different entitlement periods. Put together, our evidence suggests that the effect of entitlement periods is fairly small and seems to be nonexistent for 6 to 12 months relative to 1 to 6 months. This result is in accordance with our previous work in Fitzenberger and Wilke (2006b) and the results reported in van den Berg (1990), because the latter study finds the transfer payments after the end of the entitlement periods to be more important compared to the level of initial benefits during the first two years of unemployment.

Turning to the size of unemployment benefits, we find that unemployed with a low level of unemployment benefits ( $<25$ Euro per day)) show longer unemployment durations and unemployed with a high level ( $>40$ Euro per day)) show shorter unemployment durations (mainly in the upper part of the distribution) compared to the reference group 25-40 Euro. The hazard rates for those with the lowest benefit level are much lower at short elapsed durations and decline much less compared to the two other groups. At long elapsed durations of unemployment the hazard rates converge for the three benefit levels. This evidence can be rationalized by nonstationary search theory considering that individuals with the lowest benefit level are the most likely to be eligible for (supplementary) public assistance and their offer wage distribution is worse than for the two other benefit groups. In addition, the offer wage distribution in the low wage labor market is less likely to deteriorate with elapsed unemployment duration because of wage floors (rigid union wages or wages not falling below the level of public assistance). These considerations can explain that both the level of hazard rates and the decline in hazard rates increases with the benefit level. Furthermore, it is clear that it would be difficult to rationalize these findings based on stationary search theory. 

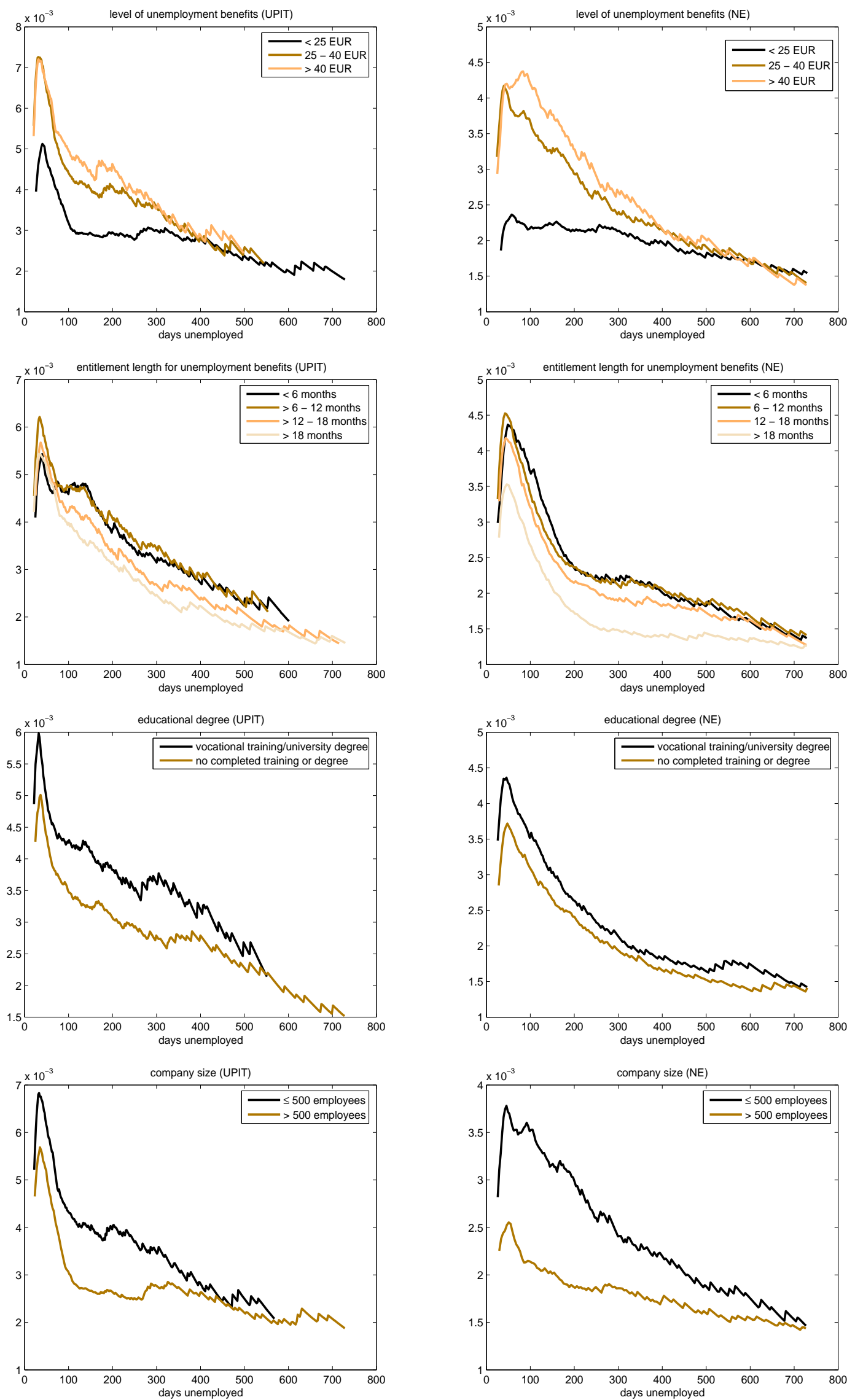

Figure 2: Estimated conditional hazard rates a the sample means of the other regressors. 


\subsection{Post Unemployment Earnings}

We analyze the determinants of post unemployment earnings with a focus on unemployment benefits and benefit entitlement using various nonparametric and parametric estimates. We first estimate standard earnings equations and then investigate mobility in the earnings distribution.

The following Tobit regression model is estimated as a way to assess the impact of individual covariates on future (post-unemployment) earnings $w_{f}$ :

$$
\log \left(w_{f}^{*}\right)=\alpha+\beta^{\prime} x_{1}+\gamma^{\prime} 1_{\text {entitlement period }}+\delta^{\prime} x_{2}+\epsilon,
$$

where $w_{f}^{*}=\min \left\{w_{f}, c\right\}, x_{1}$ is a vector of exogenous observable variables, and $x_{2}$ is a vector of variables which control for the unobserved heterogeneity (daily UB transfers, the duration of unemployment, and other work history variables). $\epsilon$ is the error term. The censoring of the wage distribution from above ( $c$ is the topcoding value) is due to the upper threshold for social security taxation above which wages are not reported.

$1_{\text {entitlement period }}$ is a $3 \times 1$ vector for the UB entitlement periods. We choose the individuals with less than 6 months entitlement period as reference category and model the effect of longer entitlement periods as a piecewise linear. We include the actual length of the unemployment spell and the fitted median unemployment duration derived from the foregoing nonlinear quantile regression model. The actual unemployment duration controls for the endogenous sorting of the unemployed over elapsed duration of unemployment and the effect of luck. The median unemployment duration reflects the endogeneity of reservation wages with respect to the offer wage distribution. This way, we control for sorting and endogeneity in order to approximate the causal effect of benefit entitlement periods on post unemployment earnings as an indicator of the quality of the job.

Table 4 show that the entitlement periods have no effect on post-unemployment earnings. Only for 6 to 12 months of benefit entitlement, there is a small positive effect of around $4 \%$ for UPIT but such an affect can not be found for NE. All other coefficients for entitlement periods are insignificant as well. This result of basically no effect of entitlement periods is consistent with the findings of Fitzenberger and Wilke (2006b), whereas they differ from Gangl (2002) for Germany. ${ }^{31}$

\footnotetext{
${ }^{31}$ In Fitzenberger and Wilke (2006b), there is no apparent effect of the unemployment insurance on post unemployment wages. However, the analysis in the first paper uses all unemployment spells in the IABS and maximum entitlement length instead of actual entitlement periods for unemployment benefits. For this reason the estimation results are likely to be different from the effect of actual entitlement periods. Gangl (2002) use rather different methods and samples drawn from survey
} 
Figure 5 (top) present nonparametric evidence for the mean relation between the length of unemployment and the position in the post unemployment wage distribution $F_{\text {post }}$ (without further controls). It is obvious that there is a negative relationship. Estimation results of the Tobit model which are presented in table 4 support this rather descriptive evidence. Our observation should, however, not be understood in causal way since we do not control for pre-unemployment wages and unobserved factors are likely to affect estimation results.

As an alternative approach, we estimate the percentile position of all pre- and post unemployment wages in the yearly IABS wage distribution of full time employees. Then, we compute the percentile change of the wage position before and after unemployment, i.e.

$$
\Delta F=F_{p o s t}\left(w_{f}\right)-F_{p r e}\left(w_{p}\right),
$$

where $F_{\text {post }}$ and $F_{\text {pre }}$ are the IABS marginal earnings distribution in the year of job loss and in the year of exit from unemployment, respectively. $w_{f}$ and $w_{p}$ are observed future and pre-unemployment earnings. The descriptive summary of $\Delta F$ can be found in table 5. Apparently, a large share of unemployment periods result in higher wage positions after unemployment than before unemployment. Fitzenberger and Wilke (2006b), who consider all unemployment spells which begin in the period 1981-1995, find an increase change in the percentile positions after unemployment in their descriptive analysis. In contrast, we find a slight decrease of about $3 \%$. However, a regression for $\Delta F$ shows that this descriptive finding may not hold at the individual level (see table 6). As before we do not obtain any evidence that longer entitlement periods for unemployment benefits are associated with larger wage increases after unemployment, confirming our above conclusions.

In contrast, nonparametric evidence (figure 5 , bottom) suggests that $\Delta F$ decreases with unemployment duration. ${ }^{32}$ This observation is supported by the regression estimates in table 6 . We obtain therefore more robust evidence that long term unemployment and lower post unemployment wages may be negatively related even when we control for unobserved components. Two further coefficients should be commented upon: First, the coefficient of having a completed educational degree is not significant. Second, the coefficient for very low unemployment benefits is highly positive, which indicates that the unemployed in this group do not exit to employment as long as the data with its well known drawbacks and limitations compared to administrative data such as limited sample size and lack of precise information about entitlements for unemployment benefits. Results are therefore not directly comparable.

${ }^{32}$ There is a significant monotonic decrease during the first two years of unemployment. 
offer wage does not lie sufficiently above the level of public assistance. Similar strong effects of reservation wages on unemployment duration in the group of recipients of public assistance were already observed by Christensen (2005) using household survey data with information about reservation wages. This is also in accordance with our reasoning above why this group has much longer unemployment periods than unemployed with higher wages before unemployment (and equivalently with lower wage replacement ratios). Furthermore, it is worth mentioning that the definition of unemployment plays only a minor role for the results of the wage analysis.

\section{Conclusions}

This paper analyzes the determinants of unemployment duration and post unemployment wages in West Germany for inflows into unemployment during the years 1996 and 1997. We focus on the effect of the length of entitlement periods for unemployment benefits and the size of unemployment benefits. We use the IAB employment subsample augmented by information on the entitlement length for unemployment benefits and the level of unemployment benefits. Since search unemployment is not observed in the data, we use two definitions for unemployment in the data. Unemployment duration is analyzed estimating censored Box-Cox quantile regressions, which involve a huge computational effort. We compute the hazard rates implied by the quantile regression estimates using a small modification of the simulation method suggested by Machado et al. (2006). Based on van den Berg (1990), we discuss empirical implications of nonstationary search theory on unemployment duration and post unemployment duration. In light of the theoretical considerations, we suggest that estimating flexible quantile regressions of durations of unemployment is a fruitful alternative for a reduced form analysis of unemployment duration.

Our estimation results suggest that the length of entitlement periods has only a weak effect on the conditional distribution of unemployment duration. While it is generally small for short unemployment duration, it increases for the higher quantiles of the unemployment duration distribution, in particular for the older unemployed with extended entitlement periods for unemployment benefits. In contrast, one would have expected that an increase benefit duration affects in particular the lower quantiles below two years of unemployment. The estimated effects for lower quantiles are ambiguous: they are either small or results are sensitive to the definition of unemployment. Our results therefore suggest that the true effect is rather small for early quitters of unemployment, for whom chances are very small, that they do not find a 
job early in their unemployment spell. Moreover, we do not find that individuals with longer entitlement lengths for unemployment benefits have considerably higher post unemployment earnings.

There are further important effects. Unemployed with a low level of unemployment benefit transfers show much longer unemployment duration. A low level of unemployment benefits is often a proxy for supplementary public assistance resulting in a higher effective replacement ratio compared to effective replacement ratio associated with higher unemployment benefits. For this reason incentives are lower to leave unemployment. Our analysis of post unemployment earnings shows that typically the increase in wages after unemployment is higher for this group than for other groups. This underlines the importance of reservation wages in the group of recipients of public assistance as already observed by Christensen (2005). Other estimated effects related to the unemployment insurance are mainly insignificant or small. We find evidence for a negative relationship between long term unemployment and post unemployment wages which we take as evidence for a deterioration of the offer wage distribution over the course of an unemployment spell.

While the estimated effect of the unemployment insurance is rather small or insignificant, we observe that estimated coefficients with market policy relevance can vary over the two definitions of unemployment used in the paper. This highlights the importance to address data quality issues in applied econometric research. It shows that incomplete information about individual employment trajectories due to missing spell information in administrative data - even in presence of detailed information about policy interventions - may prevent us to obtain precise estimates of the effect of policy interventions. Our analysis of unemployment duration provides empirical evidence for the inappropriateness of the proportional hazard assumption which is very popular in applied duration analysis.

\section{Appendix:}

\section{A I: Numerical algorithm to estimate censored Box-Cox quan- tile regression}

To estimate a censored Box-Cox quantile regression, we adapt the procedure suggested in Fitzenberger et al. (2004) to the case of censored Box-Cox quantile regression. The procedure used in this paper involves the following steps:

1. Decide on an interval $[\underline{\lambda}, \bar{\lambda}]$ where to search $\lambda$. 
2. Estimate $\beta_{\theta}(\lambda)$ conditional on $\lambda$ for both $\lambda=\underline{\lambda}, \bar{\lambda}$ by

$$
\hat{\beta}_{\theta}(\lambda)=\operatorname{argmin}_{\beta} \sum_{i=1}^{n} \rho_{\theta}\left(T_{\lambda i}-\min \left(x_{i}^{\prime} \beta, y c_{\lambda i}\right)\right) .
$$

In the following, use only the set $\mathcal{N}$ of observations $i$ for which

$$
\lambda \min \left(x_{i}^{\prime} \beta, y c_{\lambda i}\right)+1>0
$$

holds for both $\lambda=\underline{\lambda}, \bar{\lambda}$.

3. For the set of observations $\mathcal{N}$, estimate $\beta_{\theta}(\lambda)$ conditional on a grid of $\lambda \in[\underline{\lambda}, \bar{\lambda}]$ by

$$
\hat{\beta}_{\theta}(\lambda)=\operatorname{argmin}_{\beta} \sum_{i \in \mathcal{N}} \rho_{\theta}\left(T_{\lambda i}-\min \left(x_{i}^{\prime} \beta, y c_{\lambda i}\right)\right.
$$

4. Choose $\lambda$ on the grid, which minimizes

$$
\sum_{i \in \mathcal{N}} \rho_{\theta}\left(y_{i}-\left(\lambda \min \left(x_{i}^{\prime} \beta, y c_{\lambda i}\right)+1\right)^{1 / \lambda}\right)
$$

5. In the rare number of cases, when $\lambda \min \left(x_{i}^{\prime} \beta, y c_{\lambda i}\right)+1<0$ for some observation $i \in N$ and some $\lambda \neq \underline{\lambda}, \bar{\lambda}$, we set in step 4

$$
\lambda x_{i}^{\prime} \hat{\beta}_{\theta}(\lambda)+1=\epsilon
$$

for some small $\epsilon>0$ in order to make the objective function well defined.

The linear censored quantile regressions in the approach are estimated using the algorithm BRCENS implemented in the econometric package TSP as developped by the first author, see Fitzenberger (1997). 


\section{A II: Tables}

Table 1: distribution of entitlement lengths for UB in the IABS for West Germany.

Note: rounding errors

\begin{tabular}{lrrrr}
\hline \hline & \multicolumn{2}{c}{1996} & \multicolumn{2}{c}{1997} \\
& UPIT & NE & UPIT & NE \\
\hline number of spells & 40,146 & 48,794 & 37,408 & 45,872 \\
$\leq 6$ months & $44 \%$ & $37 \%$ & $47 \%$ & $41 \%$ \\
$>6-\leq 12$ months & $40 \%$ & $44 \%$ & $39 \%$ & $43 \%$ \\
$>12-\leq 18$ months & $2 \%$ & $2 \%$ & $3 \%$ & $3 \%$ \\
$>18-\leq 24$ months & $5 \%$ & $5 \%$ & $4 \%$ & $5 \%$ \\
$>24$ months & $10 \%$ & $11 \%$ & $7 \%$ & $8 \%$ \\
\hline \hline
\end{tabular}


Table 2: Descriptive summary of the sample.

\begin{tabular}{|c|c|c|}
\hline & UPIT & $\mathrm{NE}$ \\
\hline married & $54 \%$ & $53 \%$ \\
\hline vocational training, university degree & $80 \%$ & $80 \%$ \\
\hline agriculture & $3 \%$ & $3 \%$ \\
\hline construction & $28 \%$ & $26 \%$ \\
\hline trade, food & $14 \%$ & $15 \%$ \\
\hline services, public sector & $21 \%$ & $21 \%$ \\
\hline $31-35$ years old & $24 \%$ & $24 \%$ \\
\hline $36-45$ years old & $35 \%$ & $35 \%$ \\
\hline 46-49 years old & $11 \%$ & $11 \%$ \\
\hline large company & $12 \%$ & $13 \%$ \\
\hline recall & $15 \%$ & $15 \%$ \\
\hline Mid-West Germany & $17 \%$ & $17 \%$ \\
\hline Southern Germany & $32 \%$ & $31 \%$ \\
\hline entitlement period UB > 6-12M. & $73 \%$ & $79 \%$ \\
\hline entitlement period UB > 12-18M. & $5 \%$ & $7 \%$ \\
\hline entitlement period UB > 18-24M. & $9 \%$ & $10 \%$ \\
\hline entitlement period UB > $24 \mathrm{M}$. & $0 \%$ & $0 \%$ \\
\hline winter & $45 \%$ & $43 \%$ \\
\hline year 1997 & $45 \%$ & $46 \%$ \\
\hline daily UB transfer $<25$ EUR & $26 \%$ & $28 \%$ \\
\hline daily UB transfer > 40 EUR & $13 \%$ & $13 \%$ \\
\hline spell length median & 111 & 183 \\
\hline spell length min & 1 & 1 \\
\hline spell length max & 2,178 & 2,190 \\
\hline censored & $23 \%$ & $13 \%$ \\
\hline number of spells & 10,295 & 12,165 \\
\hline
\end{tabular}


Table 3: Estimated marginal changes of conditional quantiles (in \%) with bootstrap standard errors. NE only.

\begin{tabular}{lrrr}
\hline & \multicolumn{3}{c}{ quantile } \\
\cline { 2 - 4 } variable & $-15.8(2.79)$ & $-12.7(2.60)$ & $-9.0(6.43)$ \\
\hline \hline married & $-18.0(3.31)$ & $-18.6(2.33)$ & $-14.0(8.14)$ \\
vocational training, university degree & $-28.8(8.57)$ & $-36.6(7.96)$ & $-29.0(15.02)$ \\
agriculture & $-18.7(3.95)$ & $-31.2(2.81)$ & $-31.0(9.66)$ \\
construction & $16.0(5.89)$ & $6.4(5.74)$ & $4.8(14.03)$ \\
trade, food & $21.5(6.30)$ & $15.7(5.78)$ & $15.7(13.86)$ \\
services, public sector & $23.6(5.27)$ & $20.9(4.48)$ & $16.4(13.66)$ \\
31-35 years old & $43.6(6.16)$ & $43.7(5.26)$ & $36.3(33.99)$ \\
36-45 years old & $77.4(11.67)$ & $63.5(13.86)$ & $56.5(147.77)$ \\
46-49 years old & $47.0(8.15)$ & $58.0(8.69)$ & $51.5(56.21)$ \\
large company & $-25.4(3.05)$ & $-27.4(3.28)$ & $-24.8(7.19)$ \\
recall & $-6.4(3.97)$ & $-6.4(3.66)$ & $-5.3(11.96)$ \\
Mid-West Germany & $-7.6(4.52)$ & $-7.9(4.76)$ & $-10.7(7.01)$ \\
Southern Germany & $0.67(3.26)$ & $-1.3(2.68)$ & $1.3(6.89)$ \\
entitlement period UB $>6-12 \mathrm{M}$. & $12.3(5.04)$ & $8.3(4.28)$ & $10.0(11.07)$ \\
entitlement period UB $>12-18 \mathrm{M}$. & $29.0(11.46)$ & $39.1(20.64)$ & $46.5(94.99)$ \\
entitlement period UB $>18 \mathrm{M}$. & $-29.4(21.03)$ & $-34.8(21.98)$ & $-29.8(195.21)$ \\
winter & $-9.7(2.36)$ & $-11.8(2.23)$ & $-14.7(7.00)$ \\
year 1997 & $71.2(3.16)$ & $59.6(2.15)$ & $40.2(5.91)$ \\
daily UB transfer $<25$ EUR & $-3.0(4.39)$ & $-8.8(4.05)$ & $-11.5(7.28)$ \\
daily UB transfer $>40$ EUR & & & \\
\hline \hline
\end{tabular}


Table 4: Results of Tobit regression

\begin{tabular}{|c|c|c|c|c|}
\hline \multirow[b]{2}{*}{ variable } & \multicolumn{2}{|c|}{ UPIT } & \multicolumn{2}{|c|}{$\mathrm{NE}$} \\
\hline & & t-value & & t-value \\
\hline const & 4.107621 & 0.000000 & 4.043976 & 0.000000 \\
\hline married & $-0.044212^{*}$ & -5.146006 & $-0.041395^{*}$ & -4.094121 \\
\hline voc. training/univ. degree & $0.085150^{*}$ & 10.046091 & $0.121084^{*}$ & 11.355181 \\
\hline agriculture & $-0.079133^{*}$ & -3.199710 & $-0.071254^{*}$ & -2.358123 \\
\hline construction & 0.011257 & 1.175916 & 0.018926 & 1.592678 \\
\hline trade, food & $-0.048750^{*}$ & -3.632571 & $-0.034881^{*}$ & -2.317828 \\
\hline services, public sector & $-0.026842^{*}$ & -2.071184 & $-0.024427^{*}$ & -1.709216 \\
\hline 31-35 years old & 0.002132 & 0.184195 & 0.003001 & 0.218855 \\
\hline $36-45$ years old & 0.003987 & 0.317059 & -0.018166 & -1.249449 \\
\hline 46-49 years old & -0.021617 & -1.006293 & $-0.058924^{*}$ & -2.258551 \\
\hline large company & -0.007458 & -0.489883 & -0.023134 & -1.252895 \\
\hline recall & $0.029185^{*}$ & 2.691904 & 0.024482 & 1.958401 \\
\hline Mid-West Germany & 0.001337 & 0.120759 & 0.001498 & 0.113925 \\
\hline Southern Germany & 0.004719 & 0.530154 & 0.020837 & 1.944799 \\
\hline entitlement period UB $>6-12 \mathrm{M}$. & $0.042185^{*}$ & 3.676033 & -0.000270 & -0.014025 \\
\hline entitlement period UB > 12-18M. & 0.011002 & 0.569228 & -0.000251 & -0.011860 \\
\hline entitlement period UB $>18 \mathrm{M}$. & 0.037241 & 1.517098 & 0.037268 & 1.288558 \\
\hline winter & $0.027172^{*}$ & 3.184621 & $0.035714^{*}$ & 3.573937 \\
\hline year 1997 & 0.014996 & 1.429624 & -0.004156 & -0.329732 \\
\hline daily UB transfer $<25$ EUR & $-0.227572^{*}$ & -21.924623 & $-0.220896^{*}$ & -18.514528 \\
\hline daily UB transfer $>40$ EUR & $0.304376^{*}$ & 23.428170 & $0.342067^{*}$ & 22.204962 \\
\hline length of unemployment $>3-6$ months & $-0.052960^{*}$ & -5.117364 & $-0.055397^{*}$ & -4.075046 \\
\hline length of unemployment $>6-9$ months & $-0.035986^{*}$ & -2.257697 & -0.034167 & -1.778273 \\
\hline length of unemployment $>9-12$ months & -0.025006 & -1.138349 & -0.007180 & -0.292068 \\
\hline length of unemployment $>12-18$ months & 0.009883 & 0.422999 & -0.041513 & -1.713596 \\
\hline length of unemployment $>18$ months & $-0.076820^{*}$ & 3.621366 & $-0.182297^{*}$ & -9.849390 \\
\hline fitted median $>3-6$ months & 0.023952 & 0.000000 & 0.083175 & 0.000000 \\
\hline fitted median $>6-9$ months & 0.022806 & 1.955828 & $0.032525^{*}$ & 2.207949 \\
\hline fitted median $>9-12$ months & 0.016498 & 1.099032 & -0.002608 & -0.178879 \\
\hline fitted median $>12-18$ months & 0.033896 & 1.489930 & $0.031736^{*}$ & 1.999240 \\
\hline fitted median $>18$ months & -0.072541 & -1.488609 & -0.004803 & -0.167777 \\
\hline Log-likelihood & -3177.6618 & & -7471.8268 & \\
\hline Observations; \# of censored & 7,$886 ; 18$ & & 10,$566 ; 30$ & \\
\hline
\end{tabular}

*: significant at the $5 \%$ level 
Table 5: Descriptive summary of $\Delta F$.

\begin{tabular}{lrr}
\hline \hline & UPIT & $\mathrm{NE}$ \\
\hline mean & -0.03 & -0.04 \\
median & -0.02 & -0.03 \\
standard deviation & 0.21 & 0.23 \\
share of $\Delta_{i}>0$ & $42 \%$ & $42 \%$ \\
\hline \hline
\end{tabular}


Table 6: Results of OLS regression on $\Delta F$

\begin{tabular}{|c|c|c|c|c|}
\hline \multirow[b]{2}{*}{ variable } & \multicolumn{2}{|c|}{ UPIT } & \multicolumn{2}{|c|}{$\mathrm{NE}$} \\
\hline & & t-value & & t-value \\
\hline const & -0.0068 & -0.3745 & -0.0231 & -0.9227 \\
\hline married & $0.0188^{*}$ & 3.6415 & $0.0253^{*}$ & 4.7644 \\
\hline voc. training/univ. degree & 0.0013 & 0.2084 & 0.0054 & 0.8405 \\
\hline agriculture & 0.0227 & 1.4849 & 0.0220 & 1.3833 \\
\hline construction & $-0.0188^{*}$ & -2.8001 & -0.0154 & -1.9037 \\
\hline trade, food & -0.0028 & -0.3684 & 0.0000 & 0.0010 \\
\hline services, public sector & $0.0256^{*}$ & 3.5433 & $0.0227^{*}$ & 3.4091 \\
\hline 31-35 years old & -0.0011 & -0.1693 & -0.0086 & -1.3080 \\
\hline $36-45$ years old & -0.0067 & -0.8771 & $-0.0225^{*}$ & -2.8990 \\
\hline 46-49 years old & -0.0143 & -1.0993 & $-0.0385^{*}$ & -2.9033 \\
\hline large company & $-0.0181^{*}$ & -2.0091 & $-0.0310^{*}$ & -3.0845 \\
\hline recall & $0.0158^{*}$ & 2.0760 & 0.0091 & 1.0783 \\
\hline Mid-West Germany & 0.0081 & 1.2438 & 0.0037 & 0.5777 \\
\hline Southern Germany & $-0.0130^{*}$ & -2.5131 & -0.0088 & -1.7672 \\
\hline entitlement period UB $>6-12 \mathrm{M}$. & $-0.0205^{*}$ & -2.8180 & -0.0062 & -0.6005 \\
\hline entitlement period UB $>12-18 \mathrm{M}$. & $-0.0246^{*}$ & -2.2797 & -0.0086 & -0.8717 \\
\hline entitlement period UB > $18 \mathrm{M}$. & 0.0045 & 0.3296 & 0.0075 & 0.5510 \\
\hline winter & $-0.0116^{*}$ & -2.2302 & -0.0077 & -1.5091 \\
\hline year 1997 & -0.0042 & -0.5810 & -0.0129 & -1.5719 \\
\hline daily UB transfer $<25$ EUR & $0.0792^{*}$ & 13.3330 & $0.0875^{*}$ & 15.6583 \\
\hline daily UB transfer $>40$ EUR & $-0.0152^{*}$ & -2.0899 & $-0.0273^{*}$ & -3.7791 \\
\hline length of unemployment $>3-6$ months & $-0.0349^{*}$ & -5.9957 & $-0.0321^{*}$ & -5.0719 \\
\hline length of unemployment $>6-9$ months & -0.0122 & -1.3809 & -0.0073 & -0.8187 \\
\hline length of unemployment $>9-12$ months & -0.0056 & -0.4568 & -0.0003 & -0.0301 \\
\hline length of unemployment $>12-18$ months & -0.0232 & -1.7840 & -0.0196 & -1.7483 \\
\hline length of unemployment $>18$ months & -0.0034 & -0.2895 & $-0.0194^{*}$ & -2.2649 \\
\hline fitted median length $>3-6$ months & 0.0066 & 0.5046 & 0.0111 & 0.6682 \\
\hline fitted median length $>6-9$ months & 0.0033 & 0.3984 & 0.0040 & 0.4349 \\
\hline fitted median length $>9-12$ months & 0.0040 & 0.4468 & 0.0041 & 0.5184 \\
\hline fitted median length $>12-18$ months & 0.0173 & 1.3355 & -0.0029 & -0.3426 \\
\hline fitted median length $>18$ months & -0.0006 & -0.0208 & 0.0140 & 0.9804 \\
\hline$R^{2}$ & 0.0559 & & 0.0505 & \\
\hline Nobs & 7,886 & & 10,566 & \\
\hline
\end{tabular}

*: significant at the $5 \%$ level 
A II: Figures 

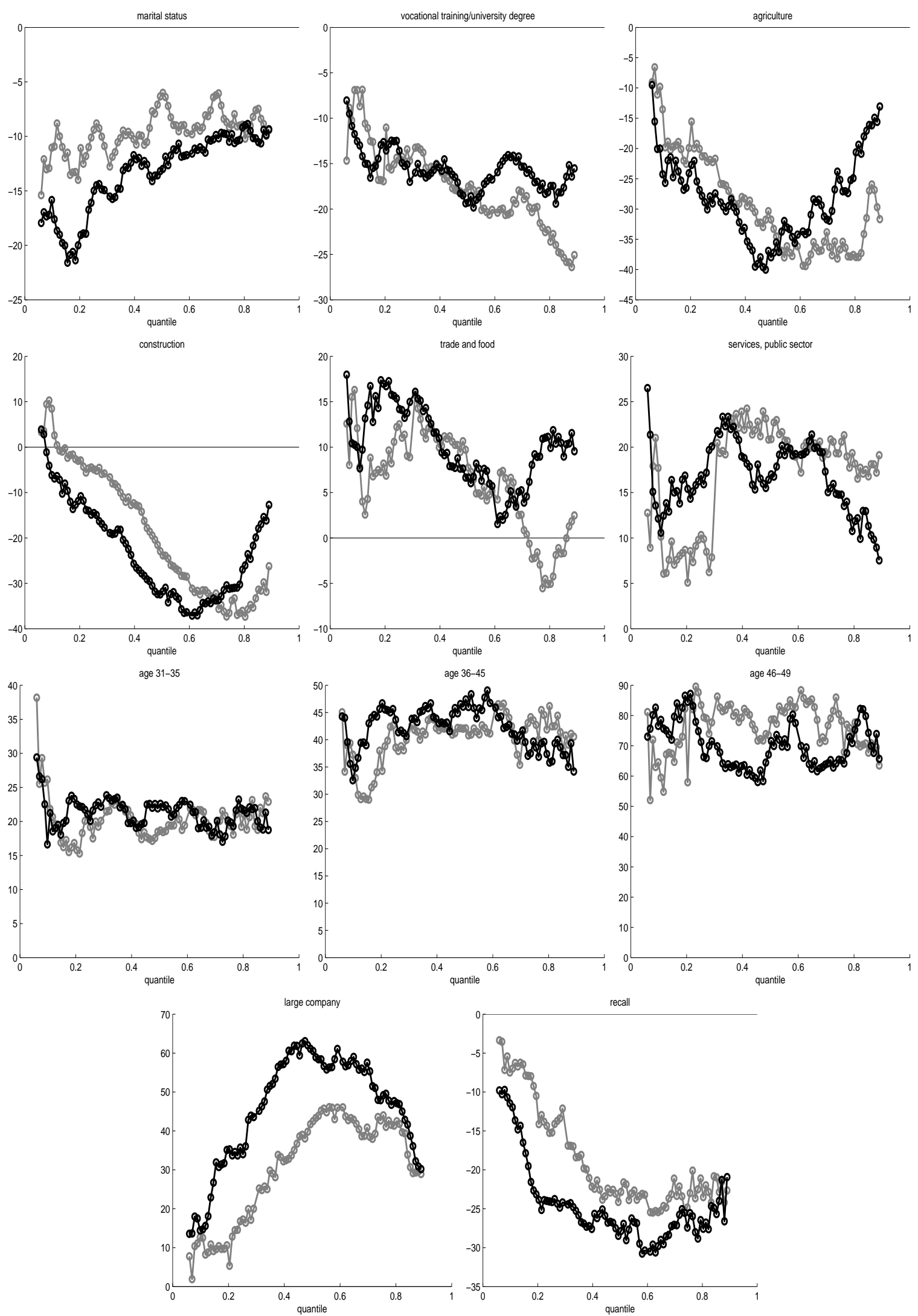

Figure 3: Estimated percentage change of the conditional quantile function at the sample means of the other regressors, black line: NE, grey line: UPIT, part I 

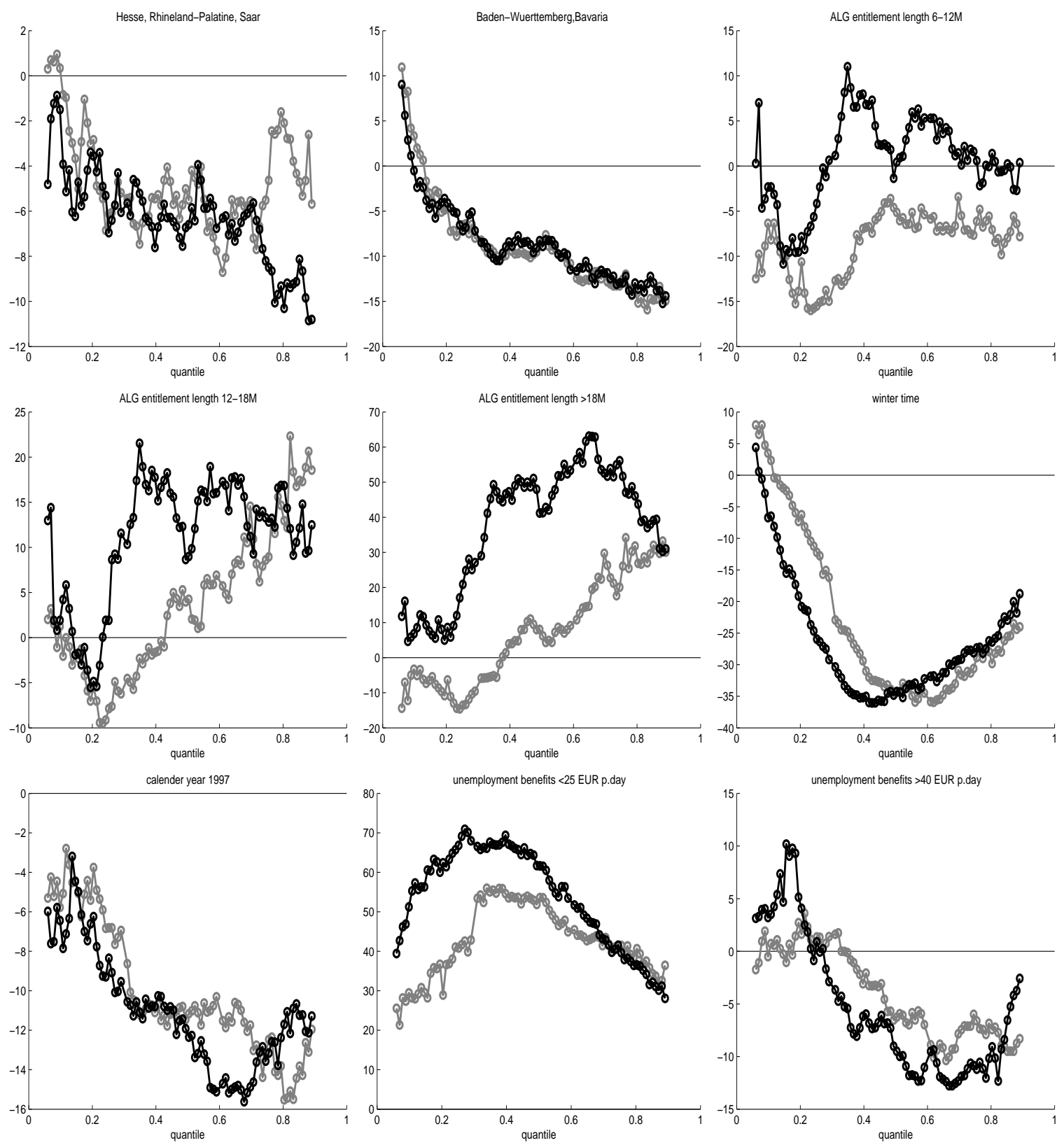

Figure 4: Estimated percentage change of the conditional quantile function at the sample means of the other regressors, black line: NE, grey line: UPIT, part II 

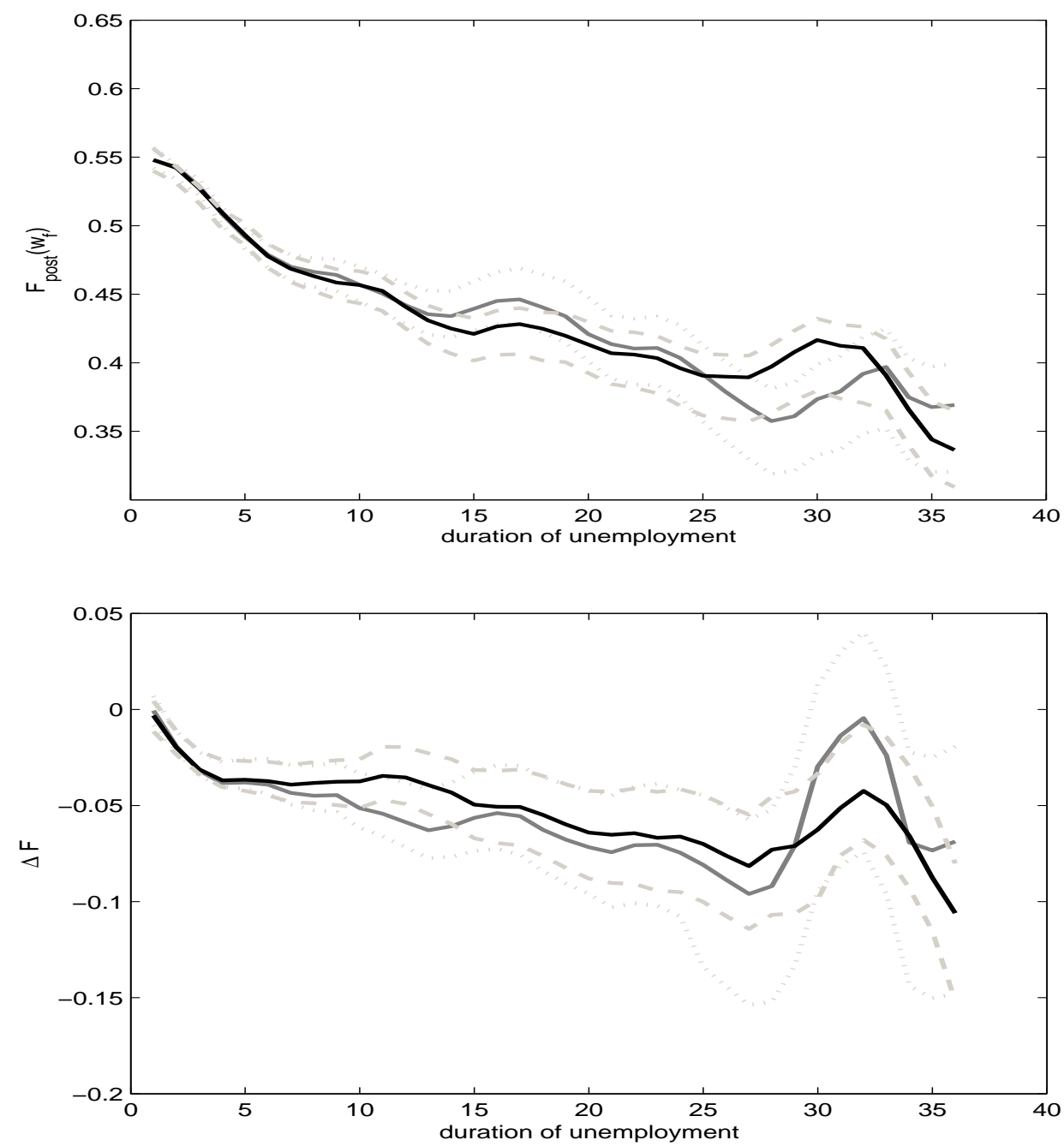

Figure 5: Nonparametric mean regression estimates for $E\left(F_{\text {post }}\left(w_{f}\right) \mid t\right)$ and $E(\Delta F \mid t)$ with $90 \%$ wild bootstrap confidence bands. grey: UPIT, black: NE 


\section{References}

Bender, S., Haas, A., and Klose, C. (2000) The IAB Employment Subsample 19751995. Schmollers Jahrbuch, 120, 649-662.

Biewen, M. and Wilke, R.A. (2005) Unemployment Duration and the Length of Entitlement Periods for Unemployment Benefits: do the IAB employment Subsample and the German Socio-Economic Panel yield the same Results? Allgemeines Statistisches Archiv, 89(2), 209-236.

Box, G. and Cox, D. (1964). An Analysis of Transformation. Journal of the Royal Statistical Society B Vol. 26, 211-252.

Buchinsky, M. (1995). Quantile regression, Box-Cox transformation model, and the U.S. wage structure, 1963-1987. Journal of Econometrics Vol.65, 109-154.

Chamberlain, G. (1994) Quantile Regression, Censoring, and the Structure of Wages. In: Sims, C. (ed.), Advances in Econometrics: Sixth World Congress, Volume 1, Econometric Society Monograph.

Christensen, B. (2005) Reservationslöhne und Arbeitslosigkeitsdauer, Jahrbücher für Nationalökonomie und Statistik 225(3), 303-324.

Decressin, A. (2001) Tinkering With or Tackling Unemployment Compensation? Working Paper No. 01-05. Georgetown University.

Fitzenberger, B. (1997). A Guide to Censored Quantile Regressions. In: Handbook of Statistics, Volume 15: Robust Inference (Eds. G.S. Maddala \& C.R. Rao), 405-437. Amsterdam: North-Holland.

Fitzenberger, B. and Wilke, R.A. (2006a) Using Quantile Regression for Duration Analysis. forthcoming in: Allgemeines Statistisches Archiv 90(1).

Fitzenberger, B. and Wilke, R.A. (2006b) Unemployment Durations in West-Germany Before and After the Reform of the Unemployment Compensation System during the 1980ties. Discussion Paper, Goethe University Frankfurt.

Fitzenberger, B., Wilke, R.A. and Zhang, X. (2004) A Note on Implementing Box-Cox Quantile Regression. ZEW Discussion Paper, 04-61.

Gangl, M. (2002) Unemployment Benefits as a Search Subsidy: New Evidence on Duration and Wage Effects of Unemployment Insurance. Discussion Paper, FS I 02-208, Wissenschaftszentrum Berlin. 
Hamann, S., Krug, G., Köhler, M., Ludwig-Mayerhofer, W. and Hacket, A. (2004). Die IAB-Regionalstichprobe 1975-2001: IABS-R01" ZA-Information 55, S. 36-42

Hujer, R. und Schneider, H. (1995) Institutionelle und strukturelle Determinanten der Arbeitslosigkeit in Westdeutschland: Eine mikroökonomische Analyse mit Paneldaten. In: B. Gahlen, H. Hesse, H.J. Ramser, editors, Arbeitslosigkeit und Möglichkeiten ihrer Überwindung, Wirtschaftswissenschaftliches Seminar Ottobeuren, 25, J.C.B. Mohr, Tübingen, 53-76.

Hunt, J. (1995) The effect of the Unemployment Compensation on Unemployment Duration in Germany. Journal of Labor Economics. Vol. 13.1, 88-120.

Katz, F. and Meyer, B. (1990) The impact of the potential duration of unemployment benefits on the duration of unemployment. Journal of Public Economics, 41, 4572 .

Koenker, R. and Bilias, Y. (2001). Quantile Regression for Duration Data: A Reappraisal of the Pennsylvania Reemployment Bonus Experiments. Empirical Economics, 26, 199-220

Koenker, R. and Geling, O. (2001). Reappraising Medfly Longevity: A Quantile Regression Survival Analysis. Journal of the American Statistical Association, 96(454), 458-468.

Jürges H (2005) Objects in the mirror are closer than they appear: Unemployment, retrospective error, and life satisfaction. Schmollers Jahrbuch 125(1):157-165.

Lee, S. and Wilke, R.A. (2005) Reform of Unemployment Compensation in Germany: A Nonparametric Bounds Analysis Using Register Data. ZEW Discussion Paper 05-29.

Lüdemann, E., Wilke, R.A. and Zhang, X. (2006) Censored Quantile Regressions and the Length of Unemployment Periods in West Germany. Empirical Economics, 31, 1003-1024.

Machado, J. and Mata, J. (2000) Box-Cox Quantile Regressions and the Distribution of Firm Sizes. Journal of Applied Econometrics, 15(3), 253-274.

Machado, J. and Mata, J. (2005) Counterfactual Decomposition of Changes in Wage Distributions using Quantile Regression. Journal of Applied Econometrics, 20(4), 445-465. 
Machado, J.A.F. and Portugal, P. (2002) Exploring Transition Data through Quantile Regression Methods: An Application to U.S. Unemployment Duration. In: Statistical data analysis based on the L1-norm and related methods - 4th International Conference on the L1-norm and Related Methods (Ed. Yadolah Dodge), Basel: Birkhäuser.

Machado, J.A.F., Portugal, P., and J. Guimarães (2006) U.S. unemployment duration: Has long become longer and short become shorter? IZA discussion paper, No. 2174 .

Meyer, B. (1990) Unemployment insurance and unemployment spells, Econometrica, $58,757-82$.

Meyer, B. (2002) Unemployment and workers' compensation programmes: Rationale, design, labour supply and income support. Fiscal Studies, 23(1), 1-49.

Moffitt, R. (1985) Unemployment insurance and the distribution of unemployment spells, Journal of Econometrics, 28, 85-101.

Müller, E., Wilke, R.A. and Zahn, P. (2007) Beschäftigung und Arbeitslosigkeit älterer Arbeitnehmer: Eine mikroökonometrische Evaluation der Arbeitslosengeldreform von 1997, Jahrbücher für Nationalökonomie und Statistik, 227(1), forthcoming.

Narendranathan W., Nickell, S. and Stern J. (1985) Unemployment benefits revisited. The Economic Journal, 95, 307-329.

OECD (2003) Benefits and employment, friend or foe? Interactions between passive and active social programmes. OECD, Employment Outlook, Chapter 4, Paris.

Plassmann, G. (2002) Der Einfluss der Arbeitslosenversicherung auf die Arbeitslosigkeit in Deutschland. Beiträge zur Arbeitsmarkt- und Berufsforschung, 255, Institut für Arbeitsmarkt- und Berufsforschung der Bundesanstalt für Arbeit (IAB) Nürnberg.

Portnoy, S. (2003). Censored Regression Quantiles. Journal of the American Statistical Association, 98(464), 1001-1012.

Powell, J.L. (1991). Estimation of monotonic regression models under quantile restrictions. In: W.Barnett, J.Powell, and G.Tauchen, eds., Nonparametric and semiparametric methods in Econometrics, (Cambridge University Press, New York, NY) 357-384. 
Schneider, H. and Hujer, R. (1997) Wirkungen der Unterstützungsleistungen auf die Arbeitslosigkeitsdauer in der Bundesrepublik Deutschland: Eine Analyse der Querschnitts- und Längsschnittdimension, in: Hujer, R. et al. (eds.): Wirtschaftsund Sozialwissenschaftliche Panel-Studien, Datenstrukturen und Analyseverfahren, Sonderhefte zum Allgemeinen Statistischen Archiv, Bd. 30, Göttingen, $71-88$

Silverman, B.W. (1986) Density Estimation for Statistics and Data Analysis. London: Chapman and Hall.

Steiner, V. (1997) Extended benefit-entitlement periods and the duration of unemployment in West Germany. ZEW-Discussion Paper No. 97-14.

Steiner, V. (2001) Unemployment persistence in the West German labour market: Negative duration dependance or sorting?, Oxford Bulletin of Economics and Statistics Vol. 63, 91-113.

Tatsiramos, K. (2006) Unemployment Insurance in Europe: Unemployment Duration and Subsequent Employment Stability. unpublished discussion paper, IZA Discussion Paper, 2280.

Van den Berg, G.H. (1990) Nonstationarity in Job Search Theory. Review of Economic Studies, 57, 255-277.

Van den Berg, G.H. (2001) Durations models: Specification, identification and multiple durations. In: J.J. Heckman, E. Leamer, editors, Handbook of Econometrics, Volume 5, Elsevier, Amsterdam, 3381-3460.

Van Ours, J. and M. Vodopivec (2006a) How Shortening the Potential Duration of Unemployment Benefits Affects the Duration of Unemployment: Evidence from a Natural Experiment. Journal of Labor Economics, 24(2), 351-378.

Van Ours, J. and M. Vodopivec (2006) Shortening the potential duration of unemployment benefits does not affect the quality of post-unemployment jobs: Evidence from a natural experiment. IZA Discussion Paper, 2171.

Weber, R. (1999) Unemployment spells and the duration of unemployment benefits. Discussion Paper No. 127. Department of Economics, University of Ingolstadt.

Wichert, L. and Wilke, R.A. (2005) Application of a Simple Nonparametric Conditional Quantile Function Estimator in Unemployment Duration Analysis. $Z E W$ Discussion Paper, No. 05-67. 
Wilke, R.A. (2004) Eine empirische Analyse von Sanktionen für Arbeitslose in Westdeutschland während der 1980er und 1990er Jahre, Zeitschrift für Arbeitsmarktforschung, 37, 45-52.

Wilke, R.A. (2006) Semiparametric Estimation of Consumption Based Equivalence Scales - The Case of Germany, Journal of Applied Econometrics, 21(6), 781-802.

Wolff, J. (2003) Unemployment compensation and the duration of unemployment in East Germany Sfb 386 Discussion Papers 344, University of Munich.

Zhang, X. (2004) Neuere Entwicklungen in der Analyse von Verweildauermodellen mit Quantilsregressionen als Alternative zum konventionellen Modell der proportionalen Hazardrate. Dilpoma Thesis. Mannheim University. 